\title{
We mapped it so you don't have to Comparing online data mapping platforms
}

A t the University of Georgia (UGA) Libraries' Willson Center Digital Humanities Lab, we often help faculty members and students create research projects using new digital technologies. We have limited resources, but great ideas, and this article will share how we have solved common mapping research questions using web tools, most of which are free and accessible to any user on or off our campus.

There are a lot of mapping platforms, both open source and proprietary, available. Each have their idiosyncrasies and limitations, and they can be difficult to fit to a specific research request. Our most common request sounds something like this: "I would like to make a map with the Neatline plugin on my WordPress site using Leaflet with a historic map basemap, a time slider, and showing four kinds of data."

For those who build maps all the time, you likely recognize that most of these elements don't go together, or would require quite a bit of custom work. It's our job to determine what is actually needed and what level of complexity is required by the data. Ideally we will be able to help this researcher create a map independently. Though we count a GIS expert as a member of our team, we recognize that this is not the norm for everyone. Therefore, we will discuss the options we most often use with researchers so that, going forward, these researchers will be able to make their own maps using any data they may create.
To help illustrate the differences and complexities of each of these tools with the types of data the researcher has, and the level of expertise they need to create their map, we have taken a set of data from an actual researcher, cleaned it, and sent it through four common mapping tools.

Our data is from a history project that looks at the movements of 66 political prisoners from Naples. ${ }^{1}$ The larger project, "The 66: A Story of Revolution, Suffering, and Escape at Sea on the Eve of Italian Unification," looks at prison reform in England and Italy in the 1850s. We started with two pieces of data: a spreadsheet with the names of the 66 political prisoners and the latitude and longitude of their hometowns, and a map of 1850 s Italy, which we georeferenced. ${ }^{2}$

We looked at the types of data each program can input, the features to display the data, and any analytics that can be performed. These are the things that faculty request most often. We are also looking for a program that can create a web-accessible map and, ideally, can offer student-level access for classroom use.

Each of the tools that we will discuss here (Google Fusion Tables, Carto, ArcGIS and its online component ArcOnline, and Neatline

Emily McGinn is digital humanities coordinator, email: mcginn@uga.edu, and Meagan Duever is GIS librarian at the University of Georgia Libraries, email: duever@ uga.edu

C을 2017 Emily McGinn and Meagan Duever 
with Omeka) can do most of these things, but each one also has a limit. ${ }^{3}$ This article will help illustrate what gets left out in each program and the extent of each one's capabilities. We will discuss these tools in order from easiest to most complex.

\section{Google Fusion Tables}

The first is Google Fusion Tables. It's very easy to

use. $\mathrm{Fu}-$ sion Tables are flexible when it comes to the form of the geo$\mathrm{graph}$ i c data. It accepts addresses with street, city, state, ZIP code (there is a Prisoner data set using Google Fusion Tables. daily limit,

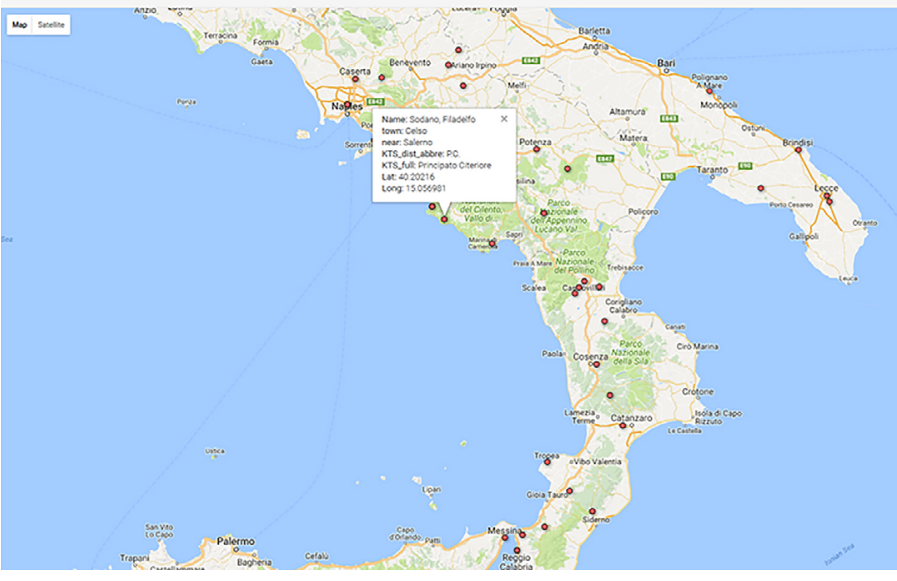

so plan accordingly), and latitude/longitude data. If you only have city, state information, Fusion Tables will place a marker in the center of that city (but only one marker per city). You can create a pop-up window from the other columns of your spreadsheet, inc $1 \mathrm{u} \mathrm{d}$ i n g images if they have a URL, but all points will have a uniform marker. The rest of your columns create a popup window to display information about each place. could disappear without warning.

\section{Carto}

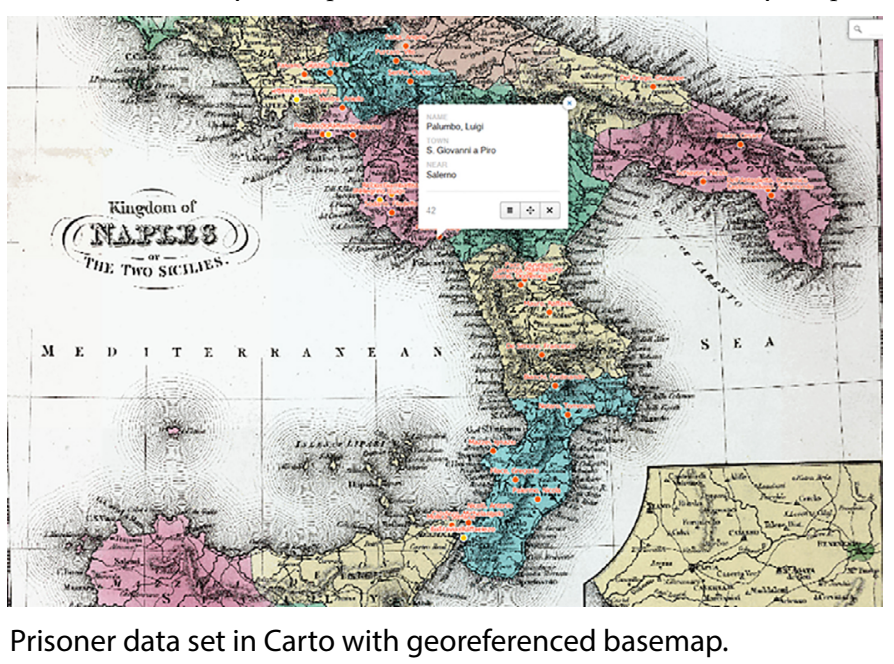

The result is a standard Google map that shows your data, but isn't really customizable. Historic basemaps cannot be added. It is a Google product and can be shared and edited by multiple people at the same time, and the end result can be embedded in a website. However, this tool is no longer supported by Google. It's great for simply testing a dataset, and even better for a classroom

project as the learning curve is fairly shallow.

We hesitate to recom mend this tool for long-term projects, as Google is no longer developing this product. While still active and available, it is no longer updated and

While Fusion Tables will create a fast, accurate, and user-friendly map, we have found Carto to be far more customizable, while remaining usable for both faculty and students. The p rog r a m is free and available on the web (although there is a paid version, the 
free account is more than adequate). Recently added to the free account is a set of "builder" tools, which allows for more customization and can be linked to a class through Git Hub. From the same exact researcher spreadsheet we used above, without changes or further cleaning, we were able to create a custom map that is much more aesthetically pleasing than the Google Fusion Tables map. We were also able to members have been able to create their own maps using this tool. With a little knowledge of SQL, CSS, or JavaScript, the maps can be even slicker. QGIS (an open source GIS platform) also has a Carto plug-in that links to your Carto account for added flexibility.

\section{ArcGIS}

The next mapping tool is the most professional and the most well-known, ArcGIS.

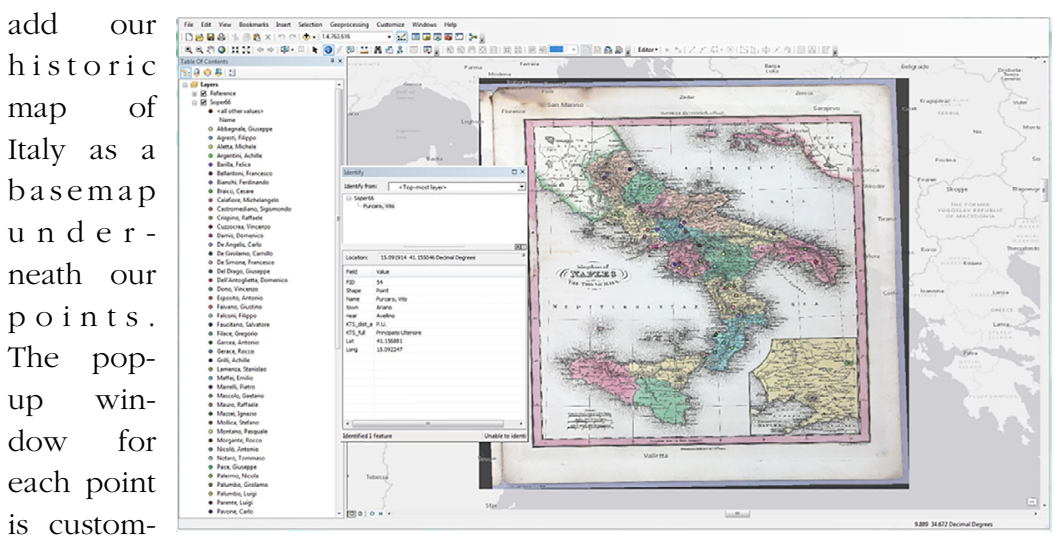

izable. Prisoner data in ArcGIS desktop.

W i $\mathrm{t} \mathrm{h}$

the new (as of May 2017) Carto Builder addition to the free account, analytic functions are now available. A time slider feature is possible (this version of our data lacked time/date information, so we were unable to try it). Another benefit is that Carto doesn't require localhosting of the maps, instead it allows a way
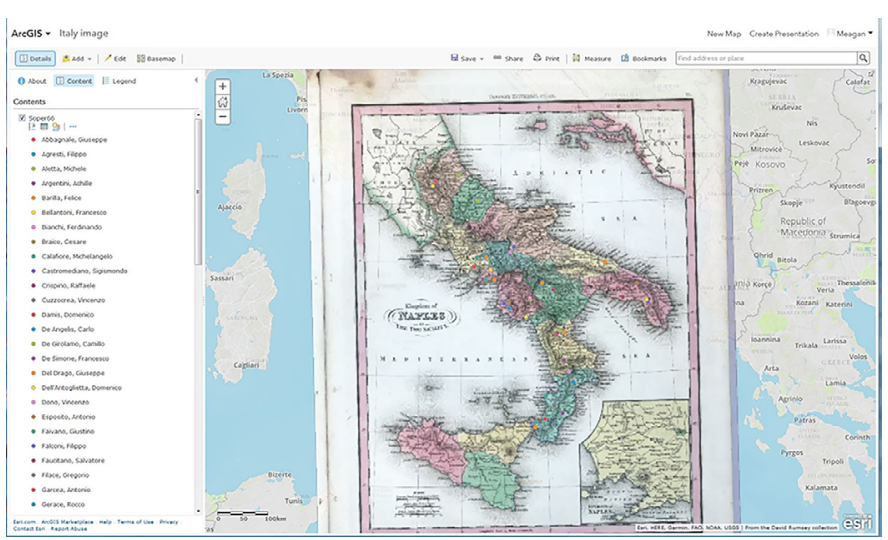

Prisoner data in ArcGIS Online with custom tile layer from Mapbox as basemap.

to embed or share the map with other websites. Carto is also being actively developed and is currently our go-to tool for having faculty members create maps. Though there's a learning curve, both students and faculty
ArcGIS is a suite of software from the company ESRI. Currently there are both desktop GIS components as well as p roducts that run on a server or a mobile device. ArcMap is the desktop component we use most often. While ArcGIS is incredibly powerful, it's also incredibly complex. Few faculty members or students in a Humanities field will come to us knowing how to use ArcGIS. If you're 1 u c c k y e $n$ o u g h to know someone who's familiar with Arc, then this tool is amazing. But it's difficult for the average person to learn quickly. This tool is built to do exactly what researchers are asking for: to use historic maps in conjunction with their own custom data, perform 
analysis, and to create web-friendly maps. Most universities have an education license with an administrator somewhere on campus, but it can still be difficult to acquire or for an individual user to access, all campus' not being created equal. ArcGIS is great for a few reasons. For one, it can do calculations. Within our prisoner dataset, we can calculate the number of prisoners from each province, their distance from other cities, the distance they travelled while incarcerated, or we could create a network analysis to show which prisoners would have crossed paths.

ArcGIS is also an industry standard. It can create high-resolution maps that are great for print publications. ArcGIS has two options to turn these static maps into interactive web versions.

One way is through the ArcServer component of ArcGIS that is an add-on to your university site license. ArcServer is not for the faint of heart, even for those fairly proficient with ArcMap. The easier and less complex way is to incorporate ArcGIS Online, another subsidiary of ArcGIS.

ArcGIS Online is a cloud-based mapping platform. Users can be added through the site license, or they can create an ArcGIS Public Account. The public account is more limited in its capabilities-including the limit of 1,000 features, no dynamic analysis-but is fine for most projects.

We have found that the most efficient way to create incorporate ArcGIS is to create our shapefiles and georeference our maps using the ArcMap desktop application, zip them, and import them into ArcGIS Online for styling. The ArcGIS Online maps can be shared and embedded into websites. We can create complex maps with the sophistication of ArcGIS but in a size that makes more sense for the web. ArcGIS does offer web app templates and the ability to add your own web apps that allow for end user input. These apps offer the opportunity for students to add input to the map from their smartphone or tablet without having to provide them with software.
ArcGIS has a number of components available, and its complexity reveals the infrastructure necessary to create some of these maps. At its most complex, ArcGIS requires a license, a specific server setup, server space to host all of the data you create, and a website in which this data can be embedded.

In short, ArcGIS does great work, but requires quite a bit of work behind the scenes. Also ArcGIS requires a PC, as it does not run on Apple products.

However, at its simplest, users can access ArcGIS Online and use the pre-existing web apps. With these the researcher can access things like timelines and story maps, but loses the ability to customize the web components.

In the long run, we find investing in learning ArcGIS (or its open source alternative QGIS) to be the most advantageous, but these tools can certainly be used at a more basic level.

\section{Neatline}

Finally, we have Neatline, which we have found is the most recognizable by faculty members.

Although Neatline is easy to use on the front end, we have listed this tool last as it requires more infrastructure on the back end than it might appear from its end products. There are positives to Neatline that we do not get in the other programs. The most important to us is the ability to give students individual access to the map. In a classroom setting students can each add their own prisoners by hand, or create their own custom data.

One important consideration for Neatline is that you can only build maps inside of another tool called Omeka. Omeka is typically used to create web exhibits of some sort of collection or grouping of things called items.

In our case, each prisoner would be an item, and we could then import each item/prisoner into Neatline to create a map. Omeka offers a free web version at Omeka. 
net, but to use the Neatline plugin to its full advantage, Neatline requires either a local install that includes a geoserver or thirdparty hosting from a company like acuGIS that will set up a geoserver and host your data. (This option is a good one if resources are limited and there is no local expert.)

$\mathrm{O} \mathrm{n} \mathrm{e}$ Omeka is installed, we can use the same historic map, and we can still use the same historic spreadsheet, but the only complication is that Omeka does not import latitude and longitude. While it will carry over all your metadata, and information for your popups, you will have to make the points by hand. Though it's not ideal, it's good for classroom use. It's easy for students to use and comes with a time slider option, which our professors really like.

Neatline does not allow for any analytics, nor does it allow for the export of the data. Once it is in Neatline, it's there to

\section{Web-based mapping tools}

Google Fusion Tables, https:// support.google.com/fusiontables/answer/2571232

Carto, https://carto.com

ArcGIS, https://www.arcgis.com/ features/index.html

Neatline, http://neatline.org/plugins stay. Migration to another platform is not an option.

\section{Conclusion}

We have used all of these options (and a few more) in our work with students and faculty at UGA. There are benefits as well as complications to each of these programs. We find that discussing the actual needs of the project up front and discussing the benefits of each program directly with the faculty $\mathrm{m}$ e $\mathrm{m} \mathrm{b}$ e $\mathrm{r}$ helps us to focus the project and produce the necessary results.

As often as possible, rather than building the project for our researchers, we help the researcher learn the tool that they need. That way, the projects are theirs, and we're here to help them with whatever specific piece they need for their work. As part of our job, we take the time to seek out and learn new technologies as often as possible, and we do our best to bring the most useful and the most appropriate tools to our faculty.

This landscape changes rapidly and often. While we are always looking for the next great thing, the core of all of these projects is the geographic data. As we have shown here, the wrapper may change, but the underlying data, our spreadsheet with geographic information, is the constant. If this basic is well formed, we can preserve this work and recreate it again in the future,

(continues on page 524) 


\section{A private Lincoln and Civil War collection,} amassed over the past 50 years by Frank J. Williams (former Rhode Island Chief Justice and nationally known Abraham Lincoln authority), will be donated to Mississippi State University (MSU). Williams, the longtime president of the Ulysses S. Grant Association, was previously instrumental in relocating that group and its own archives to MSU nine years ago. The Frank J. and Virginia Williams Collection boasts rare historical memorabilia; priceless artifacts; original, signed documents; ephemera; books published over a span of 150 years; and both original one-of-a-kind, and early massproduced, artwork relating to Lincoln and the Civil War era. The collection, which the Williamses will officially gift to the MSU Libraries, has been valued at nearly $\$ 3$ million. Committing themselves to providing perpetual support to maintain, study, and publicly display highlights from the collection, the Williamses have also offered a promised gift of $\$ 500,000$ for the creation of the Frank J. and Virginia Williams Research Fund-an endowment to MSU to curate the material in the years to come.

\section{Acquisitions}

\section{The George Clulow and United States Play-} ing Card Company Gaming Collection-one of the world's premiere collections of books about card games, games of chance, playing cards and chess-has been acquired by Vanderbilt University Libraries. The collection of approximately 1,000 volumes dating from the 15 th to the 20th century was acquired from The United States Playing Card Company, which bought the bulk of the collection from the English playing card maker George Clulow

Ed. note: Send your grants and acquisitions to AnnChriste Galloway, production editor, C\&RL News, email: agalloway@ala.org. in 1898 and have augmented and enhanced it over the past 100 years. Also included in the collection are archival records that document the development, design, and manufacture of playing cards in America. Playing cards probably originated in China, though the earliest literary reference to a card game suggests an Arabic source. The books in the new Vanderbilt collection come largely from England, France, Germany, Italy, India, Spain, Switzerland, and the United States. Subjects from the collection that lend themselves to teaching and research include the economics, mathematics, and social consequences of gaming, as well as the legal ramifications. Art students will be interested in the art of playing card design and students of mathematics and statistics will appreciate the tracts on the ambiguities and science of games of chance. In addition, there are theological diatribes and literary treatments related to gaming. $\mathrm{z}$

("We mapped it...," continues from page 490) regardless of the changes to the mapping tools themselves.

\section{Notes}

1. To read more about this project, see History professor Steven Soper's conference paper "Prisoners on the Stage of International Politics: The Evidence from Risorgimento Italy," academia.edu/33521255/Prisoners _on_the_Stage_of_International_Politics _The_Evidence_from_Risorgimento_Italy.

2. We georeferenced the map (connected the historic image to current coordinates) in ArcGIS desktop. There are a number of tutorials available online for georeferencing in ArcMap and QGIS as well as free web tools like Map Warper at http://mapwarper.net/.

3. A glossary of terms and tables of platform features is available at http:// digi.uga.edu/wp-content/uploads /sites/9/2017/09/Glossary-of-Terms.pdf. $\boldsymbol{n}$ 